\title{
CORRESPONDENCE
}

\section{Badgers and TB}

SIR - I refer to the letter by Dr Stephen Harris in your issue of 11 December 1980 (p.532) which, while critical of certain aspects of Lord Zuckerman's Report to the Minister of Agriculture on "Badgers, Cattle and Tuberculosis", agreed with his basic conclusion that the badger is a major reservoir of bovine tuberculosis (TB) in some areas of South-West England. The main criticism was that, while the reservoir constitutes a potential danger to cattle in limited areas, there is no "scientific evidence" to justify the deduction that the level of tuberculous infection in badgers in the South West is "dangerously high" and may result in spread of the disease to adjacent populations.

Since Dr Harris writes for and on behalf of the Mammal Society, it may be appropriate to ask whether all the interested members of that society would fail to be convinced by the evidence. More than 4,000 badgers were examined in connection with official investigations in the years 1971-79 and 14 per cent at least harboured Mycobacterium bovis (Report: para. 130). Of animals found dead since 1972 in fields, woods and farms in Gloucestershire, Avon and Wiltshire, 54/194 ( 28 per cent) were found to be tuberculous. Of those killed in Gloucestershire, predominantly on the roads and presumably by chance, during this period $1976-80,21 / 232$ (9 per cent) were tuberculous; this admittedly was the highest recorded prevalence by county but for the whole of the South West the figure was still 4.2 per cent (Report; Table 3 ).

These figures should be a cause for concern when dealing with a social animal which occupies, for much of the time, confined spaces underground and whose movements above ground favour between-group contacts Bovine tuberculosis in badgers is sometimes a rapidly progressive, lethal disease, the causal organism probably being excreted by many routes in large numbers 1,2 . It has, therefore, ample opportunities for transfer and by any objective epidemiological standard the risk of spread to neighbouring badger populations must be considerable. The onus for showing that this is not a reasonable interpretation should rest on others.

The argument advanced by Dr Harris, that the recent decline in the incidence of tuberculosis in cattle in the South West is simply a reflection of a general downward trend in the figures for England as a whole, misses the point that the incidence of herd "breakdowns" in the South West, in the years 1974-80, has never been less than five times that for the rest of England (Report; Table 19).

Many anomalies in the data were highlighted in the Report, which pointed out

\section{From the Mammal Society:}

In the letter from the Mammal Society on badgers and TB published on 11 December, the statements appear to be attributed to Stephen Harris. I wish to make it clear that the letter is a Mammal Society view and that Stephen Harris was only personally involved in the communication of the letter to the Editor. - J. R. Flowerdew, Hon. Secretary. the need for continuing investigation and research. In this connection it is difficult to see how the "subtle factors" twice mentioned by Dr Harris as significant in the spread of the disease from infected badgers, could be elucidated without extensive sampling on a statistically significant scale. In particular, continuous monitoring of badgers on the perimeter of heavily infected areas would be necessary to prove that the disease is not spreading (Report; para. 137). It is to be hoped that consideration will be given by interested bodies as to how this could be organized, if the necessary funds were provided.

Department of Microbiology,

W. Plowright

$A R C$ Institute for

Research on Animal Diseases, Compton, Berkshire, UK

1. Gallagher, J., Muirhead, R.H. \& Burn, K.J. Vet. Rei: 98, 9.14 (1976).

2. Gallagher, J. \& Nelson, J. Vet. Rec: 105, 546-551 (1979).

\section{Museum policy}

SIR - The broader implications of cladism are not my special concern, but the study of human evolution is. Cladistics is a useful research tool, but I support L.B. Halstead's ${ }^{1}$ objections to the way it is used in the new exhibit Man's place in evolution at the Natural History Museum.

Cladistic analysis is still a relatively untried method for expressing relationships between groups, and technical details of its application are still being debated. It was devised as a conceptual framework within which one aspect of the relationlships between modern and fossil forms could be analysed. It relates groups solely on the basis of shared features, and rejects the notion that any ancestral relationship can be inferred from this evidence; such relationships are considered "unknowable". Proponents claim that only by adhering to these principles can palaeontologists frame testable hypotheses. The strengths of the method are its simplistic rigour, but therein also lie its weaknesses. In order to provide an unambiguous framework, certain assumptions have to be made. For example, speciation is recognized only as a dichotomous branching event, and more complex adaptive radiations, anagenesis and convergent evolution of morphological features are discounted. Such assumptions are unrealistic. The concept of "relatedness" enshrined in cladistics is therefore fundamentally different from the general one which implies a lineal relationship, and as used in the exhibit, it is likely to confuse, if not actually mislead, the visitors.

The contents of the exhibit also give cause for disquiet. The authors seem particularly confused about what constitutes the "habiline" and "australopithecine" groups of early hominids. Two important specimens " 1470 " and KNM-ER 1813, have been seriously misassigned. KNM-ER 1813 is consistently cited as an example of a

"habiline" and "1470" as an "australopithecine". Yet, "1470" has a cranial capacity of around $775 \mathrm{~cm}^{3}$ and is included in Homo habilis by many workers.
The cranium KNM-ER 1813 is smaller overall, and it has a cranial capacity of between 500 and $550 \mathrm{~cm}^{3}$. It has not yet been formally assigned to a taxon but its position is sufficiently enigmatic for it to have been compared, by some authors, to Australopithecus africanus, and by others, to early Homo. Howell ${ }^{2}$ has attributed KNM-ER 1813 to Homo habilis, but he also includes "1470" in the same species.

The section which deals with Homo erectus also deserves comment. Recent, and well known, discoveries in Europe and Africa have demonstrated that a much wider range of cranial morphological features is subsumed into the "erectus" group than was previously believed. Several skulls shown an apparent mixture of classic "erectus" and archaic Homo sapiens features. These new finds strongly suggest a continuous gradation of morphology from "erectus" to "sapiens". The exhibit totally ignores this evidence.

To attribute important finds wrongly is careless; to ignore "uncomfortable" evidence is dubious academic practice, and to imply that cladism is an orthodox systematic approach is irresponsible. The contribution of the Natural History Museum to science and education is too important to be compromised in this way.

B.A. WOOD

Middlesex Hospital Medical School,

London $W l, U K$

1. Halstead, L. B. Nature 288, $208(1980)$

2. Howell, F.C. in Evolution of African Mammals (ed Maglio, V.J. \& Cooke, H.B.S.) 154-248 (Harvard University Press, Cambridge, 1978).

SIR - In a recent letter to Nature (288, 208; 1980) L. B. Halstead states his convictions that human evolution was gradual, that its gene pool of the past had certain knowable characteristics, and that the ancestry of a living species can be determined with deadly accuracy. Halstead's convictions arise from his discovery of a new form of doubt, such that he can contend that "there is not any serious doubts about Homo erectus being directly ancestral to Homo sapiens". This is certainly the news Biology has waited for, the moment when the Truth can at last be known so that all this difficult and extremely tiresome theory can be dispensed with. Until now my colleagues and I had always imagined that to doubt something was "to be uncertain as to a truth or fact" and the notion that distinguishes science from, say, politics is that in science uncertainty about the truth must remain or progress ends. Halstead's discovery can only mean that he has in hand a new form of truth - a kind of truth that can be known. Many of us puzzled over what kind it might be until it finally dawned on us that it emerges from false doubt and, to honour its discoverer, I call it Halsteadian Truth. If ever again we are troubled by some theoretical matter we need only consult the oracle in Reading. Now that Halsteadian Truth permits us to know at last the way in which evolution proceeds, what extinct gene pools were like, and exactly who was whose ancestor, I confess, with sadness for years misspent, that cladistics is indeed a waste of time.

This news about the emptiness of cladistics will have a profound effect on systematics, for Continued on $p .105$ 